\title{
ACESSIBILIDADE E CAMINHABILIDADE NO ROTEIRO DA FÉ EM JUAZEIRO DO NORTE-CE
}

\author{
SILVEIRA, Plínio Renan Gonçalves da (1); \\ GOES, Gérsica Vasconcelos (2) \\ (1) Universidade Federal do Ceará, Mestrando \\ e-mail:pliniorenan@gmail.com
}

(2) Universidade de Fortaleza - UNIFOR/ Universidade Federal do Rio Grande do Norte UFRN/Prefeitura Municipal de Fortaleza - PMF, Mestre

e-mail:gersica@unifor.br

\begin{abstract}
RESUMO
O presente estudo busca lançar um entendimento sobre a acessibilidade dos logradouros públicos e a caminhabilidade no Roteiro da Fé, um circuito de peregrinação religiosa em Juazeiro do Norte-CE. Para tanto, fundamenta-se na pesquisa bibliográfica e documental, bem como na pesquisa de campo, levantando as principais características do roteiro que favorecem ou desfavorecem a caminhabilidade acessível. As conclusões desta análise procuram levar à discussão a questão da exclusão e inclusão de pessoas com deficiência ou mobilidade reduzida nos espaços urbanos e sugerem que trabalhar a caminhabilidade destes espaços, pode ser um caminho para se chegar à acessibilidade em amplo sentido.
\end{abstract}

Palavras chave: acessibilidade; caminhabilidade; Roteiro da Fé em Juazeiro do Norte-CE.

\begin{abstract}
This study seeks to understand the accessibility of public places and the walkability in the Tour of Faith, a religious peregrination circuit in Juazeiro do Norte-CE. Therefore, it is based on bibliographical and documentary research, as well as on field research, raising the main characteristics of the tour that favor or disfavor the accessible walkability. The conclusions of this analysis seek to raise the issue of the exclusion and inclusion of people with disabilities or reduced mobility in urban spaces and suggest that working the walkability of these spaces can be a way to reach accessibility in a wide sense.
\end{abstract}

Keywords: Accessibility; walkability; Tour of Faith in Juazeiro do Norte-CE.

\section{INTRODUÇÃO}

Laurel Van Horn e José A. Isola, em suas contribuições na área de turismo e acessibilidade, afirmam que as primeiras formas de viagens de pessoas com deficiência se deram provavelmente com a finalidade de cura médica, bem como direcionadas a locais de peregrinação, motivações estas, muitas vezes, correlacionadas entre si (VAN HORN \& ISOLA, 2006). A cidade de Juazeiro do Norte, no estado do Ceará, consolidou-se ao longo 


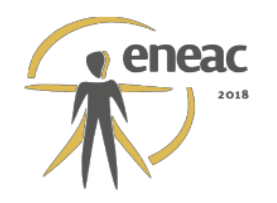

dos anos como um dos principais destinos de peregrinações de romarias do Brasil, chegando a receber 2,5 milhões de romeiros por ano, de acordo com dados da Prefeitura Municipal do município.

O presente trabalho busca apreender a configuração espacial urbana da área central de Juazeiro do Norte, mais especificamente no Roteiro da Fé, sob a ótica da caminhabilidade. O estudo procura identificar as barreiras urbanísticas e os elementos ou espaços acessíveis existentes, bem como compreender a dinâmica de usos, circulação e convívio nestes logradouros. Acreditamos que estas considerações corroboram com debate sobre a questão da inclusão e acessibilidade aos logradouros públicos das cidades brasileiras, que apesar das regulações de acessibilidade, ainda são caracterizados por inúmeras barreiras urbanísticas, dificultando ou impossibilitando o uso destes espaços por grande parcela da população. O Censo de 2010 apontou que $23,9 \%$ da população declarou ter pelo menos uma das deficiências investigadas. A região Nordeste do país apresenta índices superiores à média nacional. Em Juazeiro do Norte-CE, o Censo/2010 apontou 67.453 pessoas (correspondendo a $26,98 \%$ da população) com pelo menos uma das deficiências investigadas. Além disso, foram contabilizadas 26.392 pessoas acima de 60 anos na cidade (consideradas Pessoas com Mobilidade Reduzida), correspondendo a 10,55\% da população (IBGE, 2012).

A metodologia deste estudo desenvolve-se a partir da pesquisa bibliográfica e documental, e do levantamento de campo através da observação simples. Para tanto, foi utilizado o método de Avaliação Pós Ocupação - APO, através da técnica de "walkthrough evaluation" apresentada por Preiser et al. (1988) e que no caso específico, consistiu em percorrer o circuito e identificar os elementos penitentes à acessibilidade e à caminhabilidade, registrados através de checklists, anotações, fotografias e vídeos. Esta análise considerou critérios técnicos na identificação de barreiras urbanísticas ou espaços e elementos acessíveis a partir dos parâmetros estabelecidos nas regulações de acessibilidade (principalmente da NBR9050/2015, NBR16537/2016 e Decreto 5.296/2004), porém não procura traçar um diagnóstico de todos os itens em desacordo com as regulações e sim discutir os principais pontos de acessibilidade no roteiro sob a ótica da caminhabilidade. Para tanto, foram considerados outros critérios qualitativos de análise, à luz da literatura específica sobre o tema, como a arborização urbana, os usos do espaço, a configuração do entorno, procurando identificar trajetos e espaços mais ou menos agradáveis de serem percorridos, espaços de maior ou menor convívio etc.

\subsection{ACESSIBILIDADE E CAMINHABILIDADE EM ESPAÇOS URBANOS}

Apesar das grandes conquistas nas regulações e dos paulatinos avanços na questão da acessibilidade espacial, os logradouros públicos no Brasil são frequentemente excludentes e repletos de barreiras urbanísticas, restringindo assim o acesso de pessoas com deficiência. Silvana Cambiaghi (2007, p. 171) define barreiras urbanísticas como as dificuldades encontradas pelas pessoas nos espaços e equipamentos urbanos, tolhendo a capacidade de circular com independência pelas calçadas e ruas de uma cidade. Estas barreiras corroboram para o processo de "Exclusão Espacial", conceito desenvolvido por Cristiane Duarte e Regina Cohen em que o espaço se torna agente e autor da exclusão (DUARTE e COHEN, 2010). No contexto urbano, a manifestação da "Exclusão Espacial" vai a desencontro da função social da cidade, disposta no artigo 182 da Constituição Federal.

Salientamos, porém que acessibilidade é um conceito dinâmico e que segue em constante evolução ao longo do tempo. Muitas aplicações deste conceito acabam partindo de um princípio reducionista e técnico em função das regulações de acessibilidade, sem considerar suas múltiplas dimensões. Santiago et al. (2015, p. 11) afirma: 


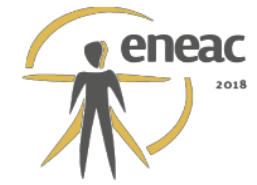

Parece-nos que não é só uma questão de atendimento às leis e normas, mas ainda falta uma cultura de inclusão, em que a percepção das reais necessidades das pessoas com deficiência e/ou mobilidade reduzida venham ser atendidas em sua plenitude.

Através de seus estudos, Duarte e Cohen (2010) também apontam que a simples eliminação de barreiras nem sempre é suficiente para se chegar a um espaço inclusivo, pois é preciso que se desenvolva afeto pelo lugar. Esta construção afetiva fundamenta-se na questão da percepção e é capaz de promover a sensação de acolhimento, pertencimento, identificação, garantindo assim a "Acessibilidade" num sentido mais amplo, representada pelas autoras com "A" maiúsculo, e alcançada quando: "[...] os espaços são convidativos, fáceis de percorrer, fáceis de entender, atrativos e, acima de tudo, são promotores de encontros e convívio com o Outro" (DUARTE e COHEN, 2010).

Seguindo este raciocínio, o conceito da caminhabilidade destaca-se como uma das propriedades dos espaços urbanos que pode ser trabalhada para que estes se tornem mais acessíveis, transitáveis e agradáveis para todos. Entendemos por caminhabilidade a definição de Roberto Ghidini (2011): "[...] uma qualidade do lugar; o caminho que permite ao pedestre uma boa acessibilidade às diferentes partes da cidade, garantido às crianças, aos idosos, às pessoas com dificuldades de locomoção e a todos" (Ghidini, 2011, p.22). A conceituação de Ghidini (2011) aponta para o conceito de Desenho Universal ${ }^{1}$, importante ferramenta para a concretização da inclusão, na medida em que expande a acessibilidade para todas as pessoas, inclusive pessoas com deficiência.

Outros autores ampliam essa conceituação de caminhabilidade, corroborando com a definição de Ghidini (2011). Raja Noriza, Raja Ariffin et al (2013) estabelecem como caminhabilidade a medida de quão amigável é o ambiente para o andar. Os autores levam em consideração a qualidade do espaço para os pedestres, condições das vias, uso do solo, segurança e conforto para a caminhada e ressaltam que a caminhabilidade é um conceito fundamental para a sustentabilidade (Noriza, Ariffin et al., 2013). Juriah Zakaria e Norsidah Ujang (2015) destacam que tanto a forma urbana quanto a estrutura das edificações do entorno, também favorecem a caminhabilidade. A obra de Jan Gehl (2013), também contribui no debate acerca da importância de a cidade ser convidativa à caminhada. $O$ autor estabelece que para ocorrer esse interesse pelo caminhar, é preciso que haja uma estrutura urbana coesa, possibilitando curtas caminhadas, espaços interessantes, seguros e agradáveis. Em outras palavras,

Outro fator muito importante é a qualidade física do espaço urbano. Planejamento e projetos podem ser usados para influenciar o alcance e 0 caráter de nossas atividades ao ar livre. Convites para uma atividade ao ar livre que vá além de uma simples caminhada incluem proteção, segurança, um espaço razoável, mobiliário e qualidade visual. (GEHL, 2013, p.21).

Acerca dos aspectos da caminhabilidade, a obra de Jeff Speck "Cidade caminhável (2016)" é uma referência para o tema. No livro, o autor aborda a chamada "Teoria Geral da Caminhabilidade". Ele estabelece que para uma cidade ter boas condições de caminhabilidade é preciso atender a quatro requisitos fundamentais: ser proveitosa, segura, confortável e interessante. O autor avança, assim, na questão da sistematização de possíveis critérios de análise. Além disso, estabeleceu o que seriam os dez passos da caminhabilidade: 01- Pôr o automóvel em seu lugar; 02 - Mesclar os usos; 03 - Adequar o estacionamento; 04 - Deixar o sistema de transporte fluir; 05 - Proteger o pedestre; 06 Acolher as bicicletas; 07 - Criar bons espaços; 08 - Plantar árvores; 09 - Criar faces de ruas agradáveis e singulares; 10 - Eleger suas prioridades.

\footnotetext{
${ }^{1}$ Conceito de design de espaços, produtos e serviços desenvolvidos para o maior número de pessoas possível, considerando pessoas com e sem deficiência, crianças, pessoas com mobilidade reduzida (idosos, obesos, gestantes, lactantes, pessoas com criança de colo).
} 


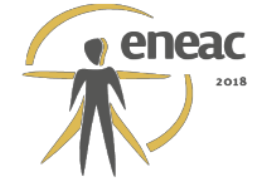

De uma forma geral, podemos afirmar que os autores supracitados trabalham, em suas conceituações de caminhabilidade, a questão da qualidade do espaço urbano. Neste aspecto, acrescentamos que os atrativos sensoriais de um ambiente incidem diretamente na questão da percepção de seus usuários, no modo como apreendem o espaço. Para Duarte e Cohen (2010), a ambiência, formada por aspectos sensoriais, desperta sentimentos armazenados na memória, constituindo um fator importante para a construção dos afetos pelo lugar. Esse processo foi definido pelas autoras como "Moldagem do Lugar", processo de construção pessoal do afeto com o espaço, que a partir da experiência e da memória, passa a ser lugar.

François Ascher (2010, p. 95) caracteriza essa qualidade multissensorial do espaço urbano quando conceitua o neourbanismo, modelo que o autor descreve como contraponto em relação ao funcionalismo simplista do urbanismo moderno:

O neourbanismo [...] leva em conta as dimensões multissensoriais do espaço e elabora não somente o visível, mas também o sonoro, o tátil e o olfativo. O desenho multissensorial das cidades permite criar ambientes diversificados, mais atraentes e mais confortáveis, inclusive para pessoas portadoras de deficiências sensoriais e motoras.

De fato, Juhani Pallasmaa (2011) aponta a extrema valorização e predomínio do sentido da visão em detrimento de todos os outros sentidos dentro da cultura ocidental, o que se rebateu diretamente na arquitetura e no urbanismo. Para o autor, a cidade moderna é a cidade dos olhos e da privação sensorial. Podemos afirmar que espaços urbanos pobres em seus aspectos sensoriais podem tornam-se menos agradáveis para caminhada ou convívio e de certa forma menos acessíveis, principalmente quando consideramos pessoas com deficiência visual e auditiva. Destacamos ainda que as poluições visual e sonora também constituem graves barreiras urbanísticas.

Em suma, uma sociedade excludente materializa-se através de espaços de exclusão quando estes não apresentam condições equitativas de acesso e uso para todos os usuários. Soluções reducionistas, crivadas pelo traço técnico da simples aplicação de normas podem não garantir acessibilidade em todas as suas dimensões. Neste contexto, entendemos que os espaços urbanos não devem ser concebidos apenas em função da sucessão de dispositivos técnicos de acessibilidade (barras, rampas, pisos táteis etc.), mas também buscando promover a caminhabilidade, o afeto, o convívio, considerando os aspectos sensoriais dos ambientes e a percepção dos usuários, concretizando, assim, a acessibilidade em seu amplo sentido.

\subsection{JUAZEIRO DO NORTE, ROMARIAS E O ROTEIRO DA FÉ}

A partir de 1872, com a chegada de Padre Cícero Romão Batista a Juazeiro, a paisagem urbana modificou-se com intensidade. Juazeiro desenvolveu-se paralelamente à personalidade do Padre, mesclando as suas histórias. O famoso e polêmico milagre da hóstia envolvendo a beata Maria de Araújo, realizado em 1889 na Igreja de Nossa Senhora das Dores ${ }^{2}$, foi o acontecimento chave que contribuiu para que o sacerdote ganhasse repercussão nacional e, sobretudo influência regional, tornando Juazeiro um importante destino religioso através das romarias (LIRA NETO, 2009).

A cidade cresceu impulsionada pelas obras encabeçadas pelo Padre Cícero (construção de açudes, ruas, estrada de ferro) e movidas pelo intenso comércio religioso das romarias: "A romaria dinamizou o comércio em Joaseiro e houve a instalação de fábricas de algodão,

\footnotetext{
${ }^{2}$ Igreja construída no ano de 1875 em mutirão organizado pelo Padre Cícero. Em 2008 foi elevada ao patamar de Basílica, passando a ser denominada Basílica Santuário de N. Senhora das Dores.
} 


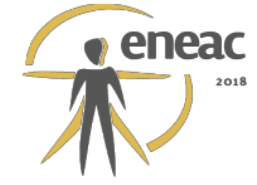

cassinos, cinemas, lojas, farmácias e instituições educacionais, muitas patrocinadas pelo Padre" (GOVERNO DO ESTADO DO CEARÁ, 2000b, p. 18).

Inicialmente o traçado da cidade se deu de forma mais ou menos ordenada, com disposição em malha xadrez, porém eventos, como a morte de Padre Cícero em 1934, impulsionaram novamente as romarias e o forte adensamento. Juazeiro começava a destacar-se não apenas pelo comércio e turismo religioso, mas como centro de negócios, polo industrial, de serviços e acadêmico. Sua malha se expande rapidamente a ponto de conurbar-se com as cidades vizinhas (Crato e Barbalha) formando o núcleo do CRAJUBAR. Recentemente, consolida-se como cidade principal da Região Metropolitana do Cariri (Lei Complementar Estadual № 78/2009) polarizando oito cidades vizinhas ${ }^{3}$. Não obstante ao fato de ter apenas pouco mais de um século de existência, Juazeiro é atualmente a terceira cidade mais populosa do estado com aproximadamente 250 mil habitantes e possui uma taxa de urbanização de 96,07\% segundo o último Censo de 2010 (IPECE, 2016).

Apesar do surgimento de novas centralidades, o centro da cidade ainda polariza todos os bairros, devido à disponibilidade de serviços, instituições públicas e comércio. É formado por grandes corredores comerciais e em ruas secundárias, o uso é predominantemente residencial. O centro, porém "[...] já apresenta vários problemas que contribuem para uma degradação da qualidade do espaço, inclusive a fuga de funções, o que provoca o seu esvaziamento noturno" (GOVERNO DO ESTADO DO CEARÁ, 2000b, p. 27). Entre estes problemas podemos citar a carência de infraestrutura básica como esgotamento sanitário, ruas e calçadas estreitas, usos conflitantes (ambulantes nas calçadas), falta de sinalização, dentre outros.

É nesta área central conflitante e em seus arredores imediatos ${ }^{4}$ que se situa o Roteiro da Fé. Este circuito - visitado com maior intensidade no período das romarias - compreende um conjunto de igrejas, praças, e demais logradouros ligados ao Padre Cícero, inclusive uma estátua de 27 metros de altura construída em sua homenagem na Colina do Horto.

As romarias evidenciam e dilatam as condições estruturais precárias da área central. $\mathrm{O}$ ordenamento dessa concentração sazonal de pessoas, mercadorias e veículos tem sido uma preocupação constante por parte do poder público. O Roteiro da Fé passou a ser comtemplado em políticas públicas do Governo do Ceara e da Prefeitura Municipal com vistas a requalificar espaços e impulsionar as potencialidades do turismo religioso. O Plano Diretor de Desenvolvimento Urbano do Município de 2000 (ainda vigente) define como primeiro componente do Plano Estratégico de Desenvolvimento que Juazeiro do Norte deverá tornar-se o maior centro de turismo religioso da América Latina e tem como diretriz: "reordenar os percursos de caminhabilidade identificados como parte de um roteiro religioso e comercial, criando um programa de novos usos e padrões de ocupação" (GOVERNO DO ESTADO DO CEARÁ, 2000a, p. 14, grifo dos autores). A partir daí elaborou-se um termo de referência para elaboração do Projeto Estruturante Roteiro da Fé, com objetivo de requalificar a área central.

Posteriormente, foi criado o Projeto de Desenvolvimento Econômico Regional do Ceará Cidades do Ceará - Cariri Central, como proposta piloto do Governo do Estado do Ceará, através da Secretaria das Cidades para o desenvolvimento regional da região do Cariri e que obteve financiamento do Banco Internacional para Reconstrução e Desenvolvimento (BIRD). Esta experiência-piloto tinha três componentes: qualificação territorial, inovação e apoio aos arranjos produtivos locais, e gestão regional e fortalecimento institucional. $\mathrm{Na}$ questão territorial, era composto de uma série de obras estruturantes para 0 desenvolvimento econômico da região, entre elas o Roteiro da Fé. A partir daí, foram realizadas diversas intervenções de requalificação urbana nos logradouros do roteiro:

\footnotetext{
${ }^{3}$ Crato, Barbalha, Jardim, Missão Velha, Caririaçu, Farias Brito, Nova Olinda e Santana do Cariri.

${ }^{4}$ Bairros do Socorro, Salesianos, Franciscanos, São Miguel e Horto.
} 


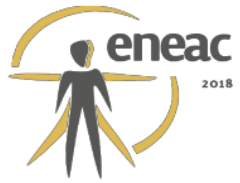

O roteiro inclui sinalização de áreas ligadas à manifestação religiosa que tem como destaque a figura do Padre Cícero. Além disso, as praças do Socorro, Salesiano, Joviano Barreto (dos Franciscanos), São Miguel, José Geraldo da Cruz, dos Ourives e da Estação estão contempladas no projeto [...] inclui também obras de pavimentação, iluminação e acessibilidade (GOVERNO DO ESTADO DO CEARÁ, 2013, p.22, grifo dos autores).

Em suma, os logradouros constituintes do Roteiro da Fé são, portanto, resultado destas e de demais intervenções que buscam o melhor ordenamento da área central e seus arredores, bem como a consolidação do roteiro de peregrinação. A consequência destas sucessivas intervenções no espaço urbano será analisada a seguir com enfoque na questão da acessibilidade e caminhabilidade.

\subsection{ACESSIBILIDADE E CAMINHABILIDADE NO ROTEIRO DA FÉ}

Neste item, serão discutidas as considerações acerca da pesquisa de campo realizada no Roteiro da Fé. Para tanto, o roteiro foi dividido em trechos (ver figura 01) a fim de melhor sistematizar nossa análise.

Figura 01 - Mapa do Roteiro da Fé - Juazeiro do Norte-CE.

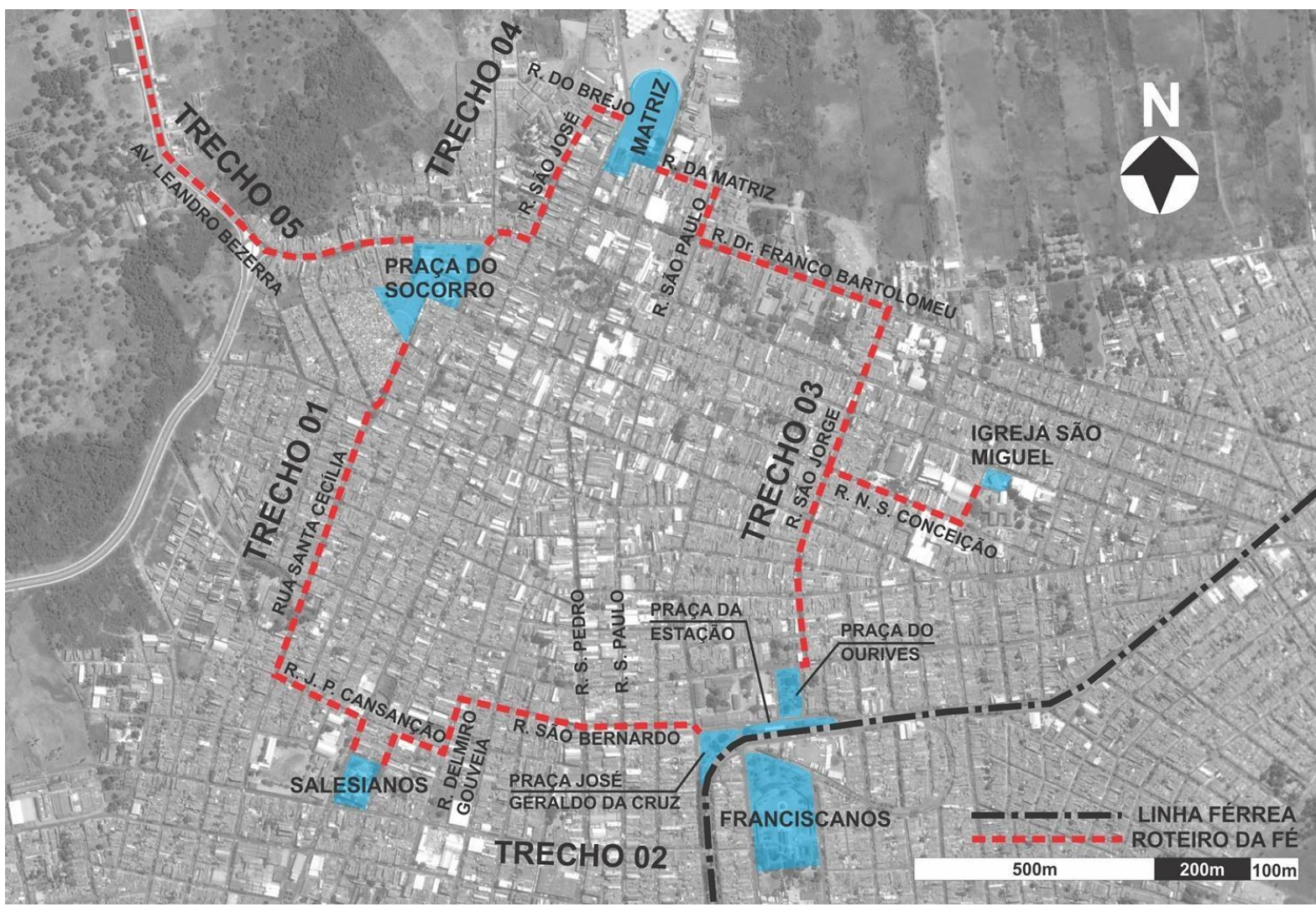

FONTE: Autores com base na imagem de satélite do Google Earth (2018).

O TRECHO 01 vai do bairro Socorro ao Salesianos. A ligação entre a Praça do Socorro e o Santuário do Sagrado Coração de Jesus é realizado pela Rua Santa Cecília, cujo uso é predominantemente residencial. A rua apresenta algumas questões de acessibilidade como: calçadas estreitas e com falta de manutenção, mobiliário e canteiros estrangulando o 


\section{$\dot{\pi}^{\text {eneac }}$}

passeio, ausência de faixas de pedestre associadas a rebaixamentos da guia, desníveis entre calçadas, rampas para automóveis invadindo o espaço do passeio. Além disso, a pouca arborização torna o trajeto cansativo em determinados trechos. Por outro lado, o uso residencial permite uma série de referências sensoriais, e em alguns trechos, grande parte das portas e janelas dá diretamente para a rua (ausência de muros). Também podem ser observadas relações de convívio no espaço público, com disposição de cadeiras nas calçadas (que acabam sendo uma extensão da casa), o que estimulam e melhoram a sensação de caminhar (ver figura 02). Na Rua J. P Cansanção as questões de acessibilidade agravam-se. A rua e calçadas são estreitas. Em determinados trechos, há ausência total de calçada e os pedestres utilizam a pista de rolagem no deslocamento. No Santuário do Sagrado Coração de Jesus, existe uma imponente igreja circundada por uma praça. Existem rebaixos para a pista de rolagem, embora situados fora das faixas de pedestres. Possui uma faixa elevada na rua a frente da entrada principal. Em determinados trechos da praça, há arborização e a ambiência é agradável, apesar da ausência de mobiliários que possam estimular o convívio. Existem estátuas religiosas nesta praça, que são acessadas apenas por escadarias, inviabilizando a entrada de pessoas em cadeiras de rodas, por exemplo. A entrada principal (frontal) da igreja também é composta por longas escadarias, e não oferece acesso principal equitativo (ver figura 02). Existem entradas através de rampas apenas nas laterais da igreja. Na parte posterior, um passeio contíguo ao muro alto da igreja constitui um trecho monótono e sem arborização ou atrativos sensoriais (ver figura 02). Embora seja possível dizer que este trecho é acessível pela ótica das normas, ele não apresenta boa caminhabilidade e não é agradável de ser percorrido.

\section{Figura 02 - Da esquerda para a direita: Convívio na Rua Santa Cecília; Escadaria no acesso frontal da Igreja dos Salesianos; Espaço posterior à Igreja dos Salesianos.}

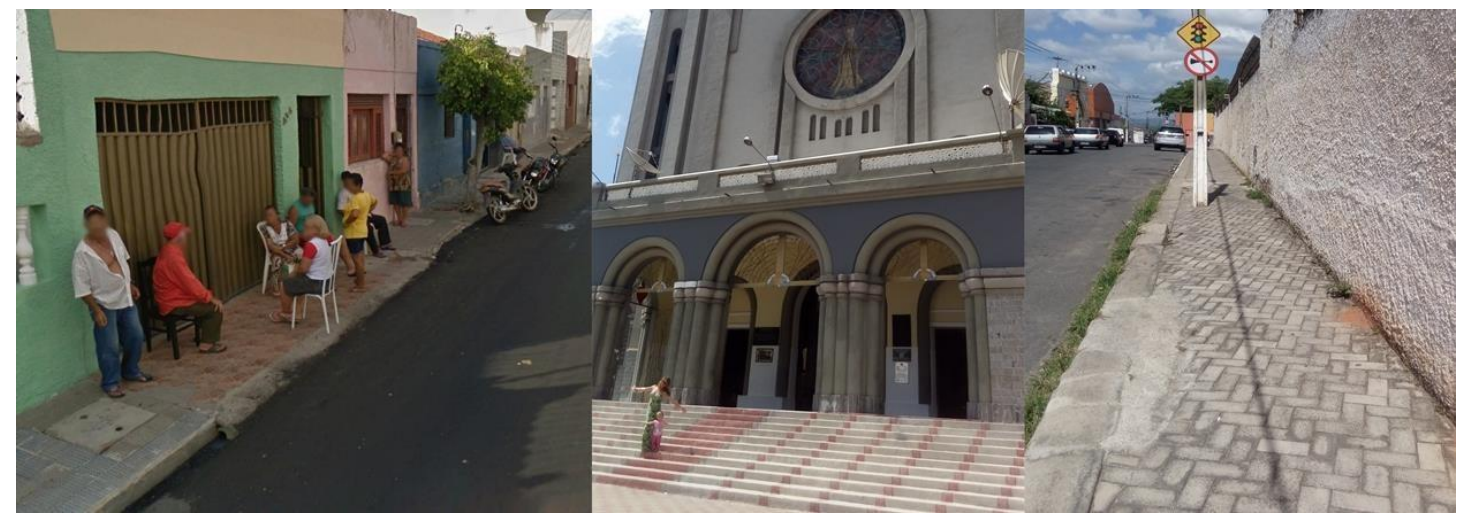

FONTE: Google Street View (a primeira) e acervo dos autores (as demais) (2018).

O TRECHO 02 vai do bairro Salesianos ao Franciscanos. O roteiro segue pela Rua São Bernardo, que no início do trajeto, possui estrutura semelhante à Rua Santa Cecília inclusive com as mesmas questões de acessibilidade - embora possamos identificar o uso misto, com algumas edificações de comércio e serviço entre as residências, dinamizando os espaços e conferindo maior vitalidade urbana. Na medida em que se aproxima do centro da cidade, o uso passa a ser predominantemente comercial. Destacamos que nesta área, apesar do grande fluxo de pedestres, cruzamentos importantes como as intercessões com os corredores comerciais da Rua São Pedro e Rua São Paulo não possuem travessias adequadas (ver figura 01). Alguns imóveis vazios também contribuem para tornar o trajeto menos agradável. A Rua São Bernardo chega até a Praça José Geraldo da Cruz. Embora também apresente algumas questões, esta praça apresenta boa acessibilidade e oferece um trajeto agradável e repleto de referências. Possui acessos através de guias rebaixadas, 


\section{巢eac}

os espaços são arborizados, possui mobiliários que incentivam o convívio, como equipamentos de ginástica, bancos etc. Também foram identificados vendedores ambulantes, equipamentos para crianças, o que torna a ambiência da praça muito agradável. A praça possui piso tátil e canteiros com guia elevada em determinados trechos, permitindo o balizamento para pessoas com deficiência visual. Esta praça liga-se à Praça da Estação através de uma faixa elevada, priorizando o pedestre em relação ao automóvel (ver figura 03). Na Praça da Estação, o acesso ao metrô é acessível. Esta praça, por sua vez, está ligada a Praça do Ourives também através de faixa elevada. Na última reforma, o espaço da Praça do Ourives foi ampliado, avançando sobre a Rua São Bernardo e diminuindo o comprimento da travessia, priorizando assim os deslocamentos a pé. Embora apresentem algumas pendências de acessibilidade como equívocos na execução do piso tátil, este conjunto de três praças interligadas representa um bom exemplo de espaço público caminhável. O mesmo não ocorre na interligação destas áreas com o Santuário dos Franciscanos devido à barreira física da linha do metrô de superfície, que impossibilita o acesso direto, por exemplo, por pessoas em cadeira de rodas (ver figura 01). Este Santuário possui uma praça à frente (Praça Joviniano Barreto) que, embora tenha boas condições de acessibilidade e arborização, é marcada pelo uso do comércio informal, principalmente durante as romarias, invadindo algumas áreas de passagem e impossibilitando alguns trajetos (ver figura 03). Na ausência do comércio, porém, o espaço torna-se vazio, pois não possui outros usos. O Santuário possui uma igreja circundada por um grande pórtico, inspirado na Praça de São Pedro no Vaticano e um átrio central. Embora a pavimentação deste átrio seja de paralelepípedo (inadequada), o pórtico circundante possui piso regular e oferece um trajeto acessível até a igreja (ver figura 03). O trajeto pelo pórtico é sombreado, protegido, agradável e oferece uma referência edificada para pessoas com deficiência visual.

\section{Figura 03 - Da esquerda para a direita: Ligação através de faixa elevada entre as Praças José Geraldo da Cruz e Estação; Praça a frente do Santuário dos Franciscanos ocupada com comércio informal; Pórtico do Santuário dos Franciscanos.}

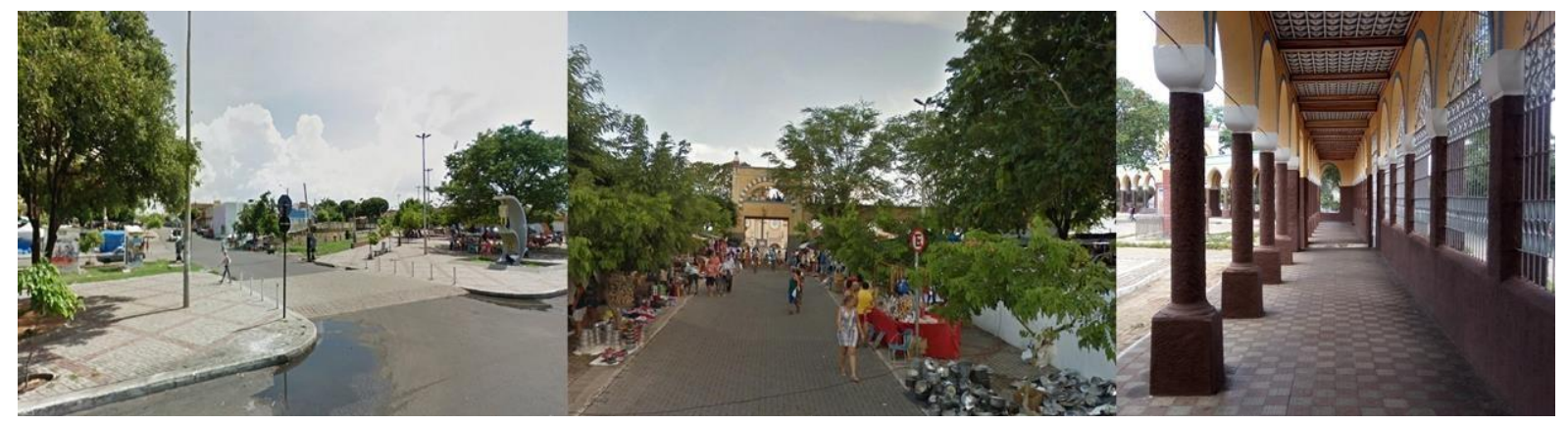

FONTE: Google Street View (a primeira e segunda) e acervo dos autores (a última) (2018).

O TRECHO 03 vai do bairro Franciscanos até a Matriz. O Roteiro segue pela Rua São Jorge e Rua N. S. da Conceição (estas apresentam as mesmas questões de acessibilidade das ruas acima) até a Igreja de São Miguel. Esta igreja está inserida num espaço de pequenas proporções e de esquina. A área tem, em geral, boa acessibilidade, com rebaixamento de guias, e rampa no acesso frontal da igreja, oferecendo acesso equitativo em relação à escadaria. O roteiro segue pela Rua São Jorge e Rua Dr. Floro Bartolomeu. Esta última possui canteiro central arborizado, apresenta longos trechos com calçadas regulares. $O$ uso misto, inclusive com locais de hospedagem para romeiros também confere certa vitalidade. $\mathrm{Na}$ Rua São Paulo e Rua da Matriz, o intenso comércio informal ocupa os passeios e parte da via (ver figura 04). Os transeuntes deslocam-se pela pista de rolagem, em conflito com veículos. O trecho é marcado por intensa poluição sonora e visual e excesso de referências, 


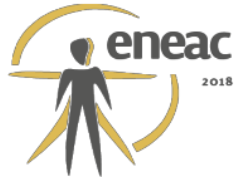

prejudicando a caminhabilidade. A Rua da Matriz segue até a Basílica Santuário Nossa Senhora das Dores (Matriz) que também possui a mesma conformação da Igreja dos Franciscanos: igreja circundada por um grande pórtico e um grande átrio central. Este átrio, projetado para comportar uma multidão, torna-se árido e sem referência para o caminhar (ver figura 04). O piso em paralelepípedo restringe o uso para pessoas em cadeira de rodas ou com mobilidade reduzida. Foram identificados alguns trechos com rota acessível sinalizada com piso tátil direcional, inclusive fazendo a interligação entre dois acessos laterais do pórtico, cruzando todo o átrio central. Internamente, na parte coberta do pórtico, existem degraus, formando pequenas arquibancadas sem acessibilidade. A calçada externa, ao redor do pórtico, é larga e regular, porém não há arborização ou qualquer outro atrativo e o clima quente torna o trajeto bastante desconfortável (ver figura 04). O acesso frontal da igreja (que dá para este átrio central) é realizado somente por escadarias. Possui rampa na lateral esquerda, porém bastante inclinada e finalizando diretamente na rua. Na lateral direita da igreja, a rampa é menos acentuada e está próxima a uma faixa de travessia com rebaixamento da guia.

\section{Figura 04 - Da esquerda para a direita: Rua da Matriz ocupada por comércio informal; Átrio} central da Matriz; Calçada externa ao pórtico da Matriz.

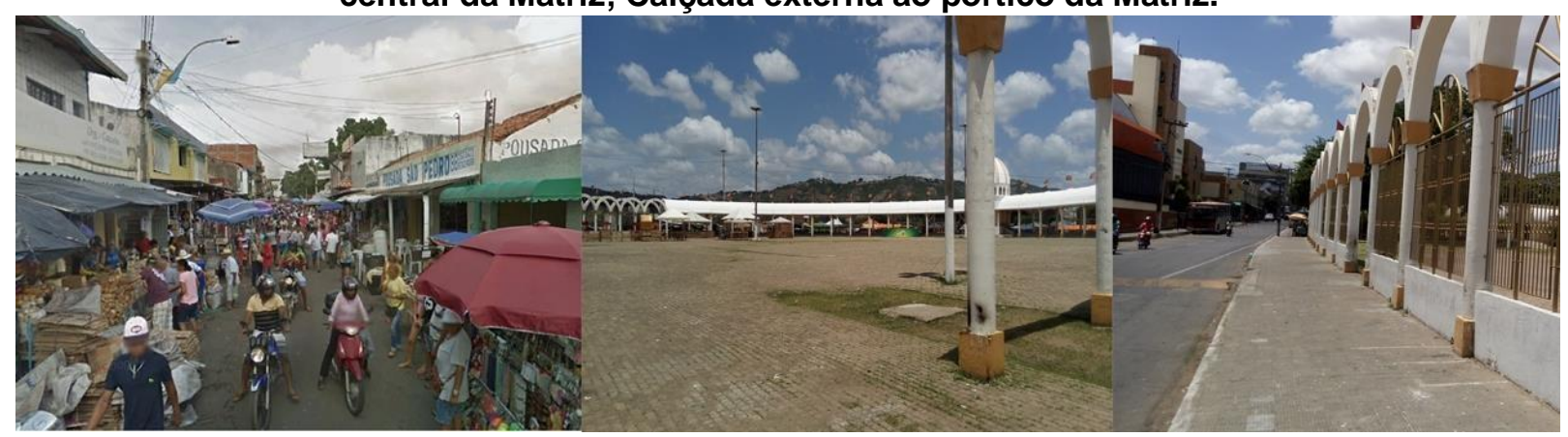

FONTE: Google Street View (a primeira) e acervo dos autores (as demais) (2018).

O TRECHO 04 vai da Matriz até a Praça do Socorro. A partir da Basílica, o roteiro segue pela Rua do Brejo e Rua São José. Estas, assim como a Rua da Matriz são densamente ocupadas pelo intenso comércio de ambulantes (ver figura 05). Pedestres e veículos disputam o espaço da pista de rolagem, dificultando ou impossibilitando a caminhabilidade, principalmente de pessoas com deficiência ou mobilidade reduzida. Estas ruas são talvez as mais movimentadas do roteiro devido a algumas edificações importantes como o Abrigo $\mathrm{N}$. S. das Dores (casa onde residiu Padre Cícero) e a casa Museu do Padre Cícero, aonde este faleceu em 1934, além de diversos locais de hospedagem. A Rua São José segue até a Praça do Socorro. Esta grande praça abriga um conjunto arquitetônico interessante. Nela está situada a Igreja N. S. do Perpétuo Socorro, que guarda o túmulo de Padre Cícero, recebendo uma grande massa de visitantes por ano e está contígua ao cemitério da cidade. A praça também abriga o Memorial Padre Cícero e boxes de comércio. Um ponto a ser destacado é que, diferente das ruas em que o comércio informal ocupa calçadas e parte da via, estes boxes foram organizados de forma que seu entorno é acessível (ver figura 05). As galerias entre os boxes são largas e permitem acesso de todos. A praça possui piso tátil e rebaixamentos de guias. A parte central da praça apresenta a mesma questão da Matriz: espaço muito amplo, árido e sem referências. Esta é uma questão difícil de ser solucionada dada a necessidade de aglomeração de pessoas, porém, na Praça do Socorro (diferente do entorno do pórtico da Matriz) as extremidades (bordas) proporcionam um trajeto mais agradável, devido ao conjunto arquitetônico (uma porção da praça foi disposta de forma contígua às fachadas dos imóveis e não a via de automóveis), além da arborização, mobiliários (bancos, caramanchões) etc. (ver figura 05). 
Figura 05 - Da esquerda para a direita: Comércio informal na Rua São José; Comércio organizado na Praça do Socorro; Ambiência da Praça do Socorro com edificações contíguas.

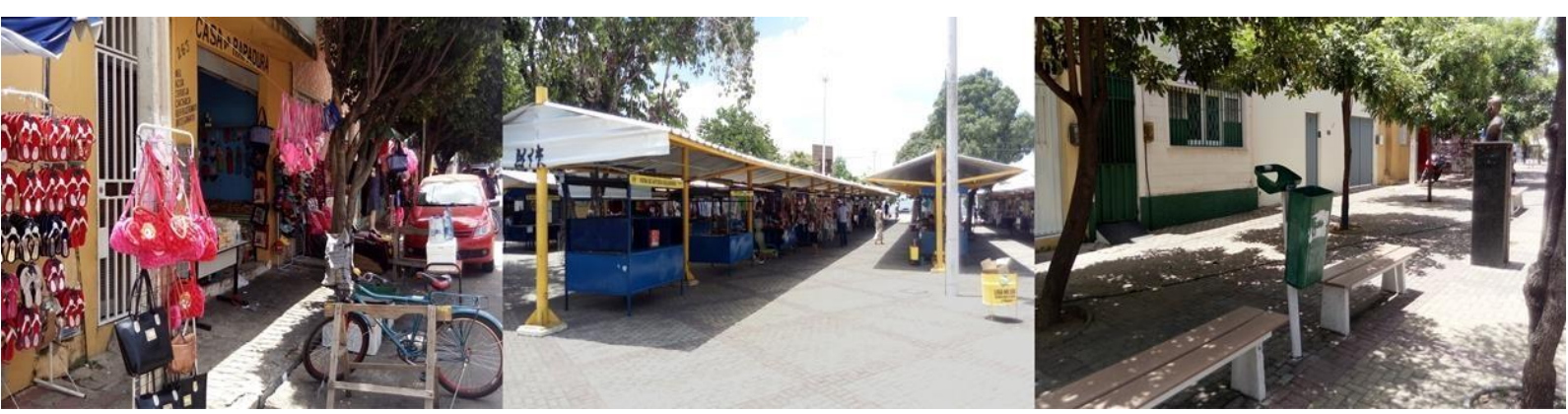

FONTE: Acervo dos autores (2018).

O TRECHO 05 vai da Praça do Socorro até à antiga estrada do Horto, bem como o espaço do Horto em si. O trecho que liga a Praça do Socorro em direção à antiga estrada do Horto é marcado pela Avenida Leandro Bezerra (ver figura 01). A parte inicial da avenida apresenta uma boa ambiência, calçadas relativamente regulares, arborização, uso misto. $O$ trecho posterior, resultado de uma recente intervenção, embora apresente calçadas em boas condições e relativamente boa acessibilidade, é extremamente monótono e sem arborização, tornando o trajeto exaustivo (ver figura 06). A estrada para o Horto, considerada uma via sacra pelos romeiros, é bastante íngreme, impossibilitando o acesso de pessoas em cadeiras de rodas. As calçadas possuem grandes desníveis (ver figura 06). Ressaltamos que existe a previsão para construção de um teleférico nesta área. O acesso ao Horto também pode ser realizado por veículos através de uma estrada asfaltada.

No Horto, o trajeto do estacionamento com vagas reservadas até o largo onde está situada a estátua de Padre Cícero é íngreme, dificultando o acesso. Neste largo, além da estátua, está situado o Casarão do Horto, que atualmente abriga um museu. De maneira geral, os espaços são agradáveis, e a ambiência provoca os sentidos do usuário. Possui arborização em alguns pontos e algumas referências para o caminhar, embora o piso em pedra portuguesa não seja apropriado e careça de instalação de piso tátil. A principal questão de acessibilidade identificada neste espaço se dá exatamente no acesso à base da estátua, local de peregrinação dos romeiros (ver figura 06). Esta é acessada apenas por um conjunto de escadarias, excluindo grande parte dos visitantes. Abaixo deste largo, existem dois andares com lojas e banheiros. Estes andares são acessados por escadas e por uma rampa. Nestes andares não existem banheiros acessíveis, apenas banheiros coletivos.

Figura 06 - Passeio da Av. Leandro Bezerra; Estrada para o Horto: Escadarias para acessar a estátua de Padre Cícero.

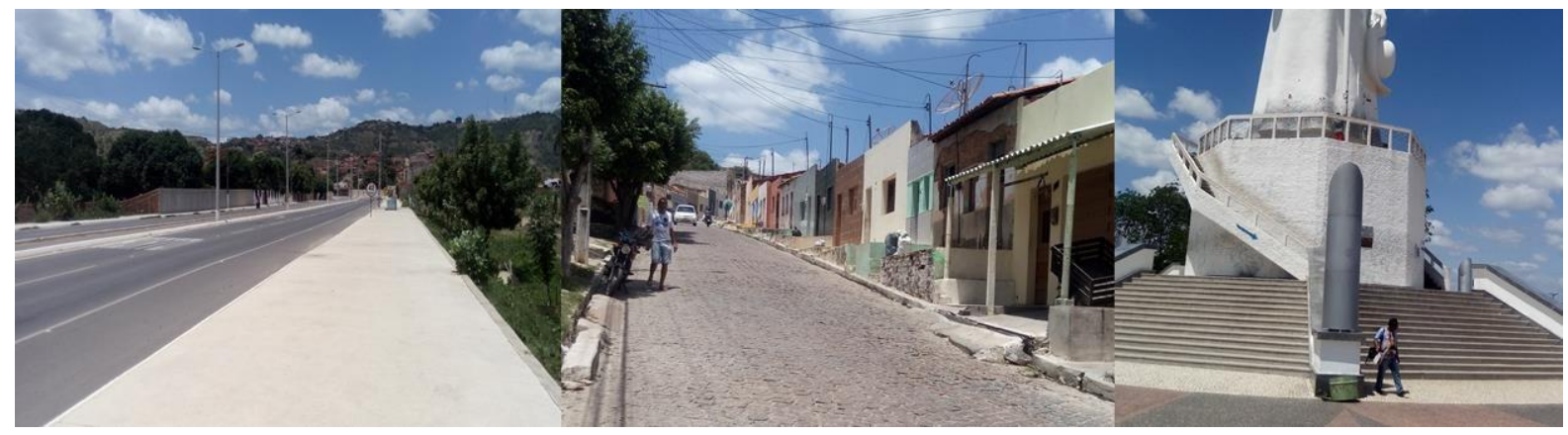

FONTE: Acervo dos autores (2018). 


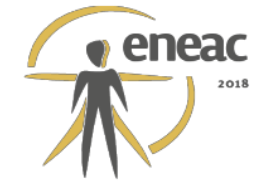

\section{DISCUSSÃO DE RESULTADOS E CONSIDERAÇÕES FINAIS}

A partir desta análise, podemos afirmar que as modificações espaciais realizadas ao longo do tempo no Roteiro da Fé avançam em alguns pontos na questão da acessibilidade e caminhabilidade. Dentre os fatores de análise que foram identificados como positivos, seguindo o aporte teórico de Jeff Speck, destacamos: o automóvel em seu lugar (com a criação de faixas elevadas e priorização dos deslocamentos a pé nas Praças José Geraldo da Cruz, da Estação e do Ourives), o mesclar de usos (usos mistos implicando em maior vitalidade e convício em determinados espaços), a proteção do pedestre (como o trajeto pelo Pórtico dos Franciscanos), a criação de bons espaços (qualidade dos logradouros públicos, como o entorno da Praça do Socorro), a arborização em alguns trechos do roteiro, as faces de ruas agradáveis e singulares (como na Rua Santa Cecília) etc. Através desses fatores, é possível captar o quão favorável é o ambiente para proporcionar a caminhada. A implantação de rebaixamentos de guias, piso tátil e rampas também apontam para os avanços no sentido de melhorar a acessibilidade espacial.

Salientamos, entretanto que estes espaços acessíveis se encontram descontínuos. Muitas são as lacunas e por isso cabem outras reflexões sobre como o espaço urbano, consolidado ao longo do tempo, inclui ou exclui pessoas com deficiência ou mobilidade reduzida. A "Exclusão Espacial" ainda se mostra através de inúmeras barreiras no Roteiro da Fé, o que finda por não proporcionar acessibilidade em amplo sentido, conforme discutido acima. Embora possamos afirmar que o roteiro é rico na questão afetiva, principalmente devido à ambiência das igrejas e aos diversos símbolos religiosos, esta apropriação torna-se mais difícil devido às inúmeras barreiras, dificultando o processo de "Moldagem do Lugar", principalmente de pessoas com deficiência ou mobilidade reduzida.

Entre os pontos negativos identificados destacamos: alguns trechos mostram-se estéreis, áridos, sem referências e embora ofereçam melhores condições de acessibilidade, não estimulam a caminhabilidade. O piso tátil possui alguns equívocos no seu traçado, além de descontinuidades. Sua cor possui pouco contraste e dificulta o uso para pessoas com baixa visão. As rampas possuem inclinação superior à máxima permitida e não possuem corrimãos adequados ou sinalização. Outra questão diz respeito ao piso em bloco intertravado, presente na maioria dos espaços, que com o desgaste e a falta de manutenção, dificulta o trânsito de equipamentos com rodas, além de oferecer baixa diferenciação de textura em relação ao piso tátil. Apesar dos rebaixamentos das guias, muitos deles encontram-se fora das faixas de travessia, não oferecendo travessia segura. Também faltam estacionamentos acessíveis devidamente sinalizados.

Um fator indispensável no planejamento destes espaços diz respeito às romarias. Milhares de pessoas e centenas de caminhões e ônibus sobrecarregam as ruas, o que torna a área central mais caótica. Os pedestres concorrem com o comércio informal disposto nas ruas e calçadas, estas já constituídas de inúmeras barreiras. Soluções que estimulem o caminhar, como a reconfiguração de ruas, destinando-as para pedestres e que possam abrigar o comércio informal, podem oferecer uma alternativa para interligar trechos do roteiro e permitir acessibilidade de forma mais contínua.

Acreditamos, por fim, que a caminhabilidade, associada ao Desenho Universal deve ser uma premissa primordial no planejamento de espaços públicos acessíveis, pois possibilitam pensar qualitativamente além dos parâmetros numéricos presentes nas normas e leis de acessibilidade, proporcionando assim inclusão através de um traço universalista, multissensorial e capaz de construir afetos. 


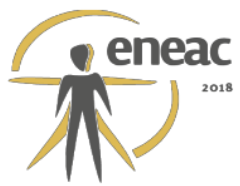

\section{REFERÊNCIAS BIBLIOGRÁFICAS}

ASCHER, François. Os novos princípios do urbanismo. Coleção RG bolso, volume 4. São Paulo, Romano Guerra, 2010.

CAMBIAGHI, Silvana. Desenho universal: métodos e técnicas para arquitetos e urbanistas. São Paulo: Editora Senac São Paulo, 2007.

DUARTE, Cristiane Rose; COHEN, Regina. Acessibilidade como fator de construção do lugar. In: Ornstein et al. (Orgs.). Desenho Universal: caminhos da acessibilidade no Brasil (pp. 81 - 94). São Paulo: Ed. Annablume, 2010.

GEHL, Jan. Cidades para pessoas. Tradução Anita Di marco. 2 ed. São Paulo: Perspectiva, 2013.

GHIDINI, Roberto. A caminhabilidade: medida urbana sustentável. Revista dos Transportes Públicos, v. 33, p. 21-33, 2011.

GOVERNO DO ESTADO DO CEARÁ. Prefeitura Municipal de Juazeiro do Norte. Plano Diretor de Desenvolvimento Urbano de Juazeiro do Norte. Juazeiro do Norte, 2000a.

Prefeitura Municipal de Juazeiro do Norte. Plano Diretor de Desenvolvimento Urbano de Juazeiro do Norte - Relatório de Questões/ Módulo Conceito. Juazeiro do Norte, 2000b.

Secretaria das Cidades. Cidades do Ceará. Edição 02. Fortaleza, 2013.

Secretaria do Planejamento e Gestão. Instituto de Pesquisa e Estratégia Econômica do Ceará. Perfil Básico Municipal 2016 Juazeiro do Norte, Fortaleza: IPECE, 2016.

INSTITUTO BRASILEIRO DE GEOGRAFIA E ESTATÍSTICA. Censo Demográfico 2010. Rio de Janeiro: IBGE, 2012.

NETO, Lira. Padre Cícero: poder, fé e guerra no sertão. São Paulo: Companhia das Letras, 2009.

NORIZA, Raja; ARIFFIN, Raja; ZAHARI, Rustam Khairi. Perceptions of the Urban Walking Environments. Procedia Social and Behavioral Sciences, v. 105, p. 589-597, 2013.

PALLASMAA, Juhani. Os olhos da pele: a arquitetura e os sentidos. Porto Alegre: Bookman, 2011.

PREISER, Wolfgang F.E.; RABINOWITZ, Harvey Z.; WHITE, Edward T. Post-occupancy evaluation. New York: Van Nostrand Reinhold, 1988.

SANTIAGO, Zilsa Maria Pinto; SANTIAGO, Cibele Queiroz de; SOARES, Thais Silveira. Acessibilidade no Espaço Público: O caso das praças de Fortaleza. In Anais do 15ํㅡㄹ Ergodesign. Recife, 2015.

SPECK, Jeff. Cidade caminhável. 1. São Paulo: Perspectiva, 2016.

VAN HORN, Laurel; ISOLA, José. Toward a Global History of Inclusive Travel. In: The Review of Disability Study: An International Jornal. Vol.II, Issue 2, pag. 5. EUA, 2006. Disponível em < http://rdsjournal.org/index.php/journal/article/view/346>. Acesso em: 02 fev. 2018.

ZAKARIA, Juriah; UJANG, Norsidah. Comfort of Walking in the City Center of Kuala Lumpur.

Procedia Social and Behavioral Sciences, v. 170, p. 642 - 652, 2015. 